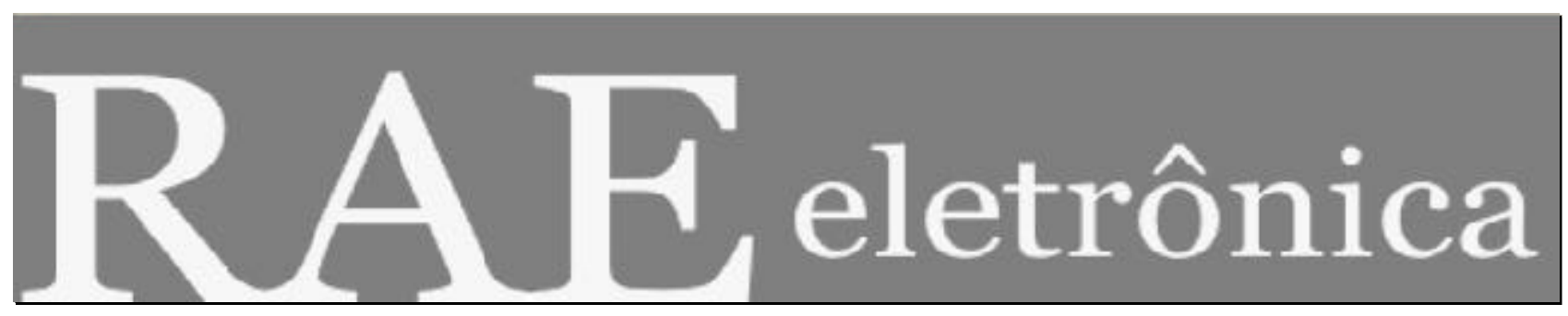

PENSATA

\title{
O ENSINO SUPERIOR E A UNIVERSIDADE
}

Por:

\section{Moema Miranda de Siqueira, UNIFENAS}

RAE-eletrônica, v. 4, n. 1, Art. 15, jan./jul. 2005

http://www.rae.com.br/eletronica/index.cfm?FuseAction=Artigo \&ID=3572\&Secao=DEBATE\&Volum $\mathrm{e}=4 \&$ Numero $=1 \& \mathrm{Ano}=2005$

CCopyright, 2005, RAE-eletrônica. Todos os direitos, inclusive de tradução, são reservados. É permitido citar parte de artigos sem autorização prévia desde que seja identificada a fonte. A reprodução total de artigos é proibida. Os artigos só devem ser usados para uso pessoal e nãocomercial. Em caso de dúvidas, consulte a redação: raeredacao@fgvsp.br.

A RAE-eletrônica é a revista on-line da FGV-EAESP, totalmente aberta e criada com o objetivo de agilizar a veiculação de trabalhos inéditos. Lançada em janeiro de 2002, com perfil acadêmico, é dedicada a professores, pesquisadores e estudantes. Para mais informações consulte o site www.rae.com.br/eletronica.

\section{RAE-eletrônica}

ISSN 1676-5648

C2005 Fundação Getulio Vargas - Escola de Administração de Empresas de São Paulo.

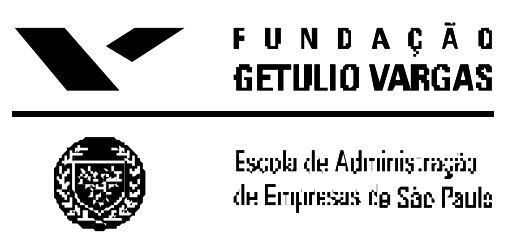




\section{INTRODUÇÃO}

Esta pensata tem o intuito de fazer algumas observações e contrapontos ao texto de Adolfo Ignacio Calderón sobre a "Emergência da universidade mercantil" (ver em "Repensando o papel da universidade", $R A E$, v. 44, n. 2, p. 104-108, 2004), sem pretender ser uma revisão conceitual ou mesmo uma resposta aos seus argumentos. As afirmações de Calderón, ao suscitarem a elaboração deste artigo, foram vistas como instigantes e provocantes - elementos primordiais para um sadio debate acadêmico. Justifica-se tal debate pelo papel que as discussões teóricas podem representar como insumo ao pensamento crítico.

Na primeira seção são apresentadas as principais mudanças e características do ambiente universitário do século XXI, ampliando a análise de Calderón ao abordar a expansão da oferta e da procura do mercado universitário no mundo e seus aspectos contraditórios no Brasil. A seção seguinte defende a tese de um espaço individualizado para a universidade no mercado multidiverso do ensino superior, distinto da "universidade mercantil" de que fala Calderón; a terceira seção especifica as exigências de qualidade de suas atividades, destacando a pesquisa relevante e o papel da pós-graduação. Por fim, a quarta seção faz considerações acerca da regulação e do corporativismo nas instituições de ensino superior, ressaltando entraves a serem superados para a eficácia dessas instituições.

\section{O AMBIENTE DA UNIVERSIDADE NO SÉCULO XXI}

É preciso reconhecer inicialmente que nas mudanças sociais, características do mundo contemporâneo, destacam-se aquelas relacionadas ao dinamismo do conhecimento e do trabalho, e suas influências diretas sobre a universidade. Assim, como ressalta Thayer no livro A crise não moderna da universidade moderna (UFMG, 2002), pensar a universidade por meio do esquema teleológico instrumental francês, ou do especulativo alemão, implica reforçar a "crise não moderna da universidade moderna". Hoje, como mostra o autor, as possibilidades efetivas do conhecimento fazem com que o saber não seja apenas dependente do acesso aos bancos acadêmicos, mas também de condições concretas de inclusão digital, tornando ultrapassada a idéia da universidade como núcleo históricoprodutivo, controlador exclusivo do saber e da sociedade. Embora o pessimismo de McLuhan (em $E l$ medio es el masaje, Barcelona: Paidós, 1987) deva ser relativizado, freqüentemente "o globo terrestre se converte numa única sala de aula, em que todos e cada um estão comprometidos em um mesmo aprendizado de vida".

\section{Mudanças na oferta}

A revolução digital não atenuou a expansão significativa do mercado de ensino superior em todo o mundo. Com o reforço de documentos oficiais de governos e de organismos internacionais - como a 
UNESCO - sobre o valor da disseminação da educação de terceiro grau como condição para o desenvolvimento sustentado de qualquer país, o modelo americano - descentralizado e mais permeável à influência ambiental - estimulou um crescimento impressionante do sistema no fim do último milênio. $\mathrm{O}$ estímulo foi focado nos seguintes aspectos: em número de instituições; tipos de titulação: licenciatura plena, licenciatura curta e seqüencial; nos modos de oferta à distância, intensivos, diurnos, noturnos; e cobertura geográfica. E tudo indica que essas características persistirão nos próximos anos. Acompanhando a tendência internacional, o Brasil aumentou a sua oferta de ensino superior nos últimos anos - expressa em número de vagas, de cursos e de estabelecimentos - atingindo de 8 a $10 \%$ de crescimento anual desde o ano de 2000.

\section{A expansão da demanda}

A demanda para o ensino superior vem se diversificando e fazendo frente à expansão da oferta, tanto pelo número e tipo de alunos - homens e mulheres, jovens e idosos, trabalhadores e desempregados quanto pela variedade de cursos e níveis procurados - graduação, pós-graduação e educação continuada.

Mesmo os críticos mais ferozes da ênfase à educação na "sociedade do conhecimento", questionando os gastos exorbitantes em educação superior - como Alison Wolf no livro Does Education Matter? Myths about Education and Economic Growth (Penguin Books, 2002) -, reconhecem a validade da educação individual como investimento produtivo. Dados empíricos mostram que um ano a mais de escolaridade resulta, em média, em um incremento de $10 \%$ na renda de uma pessoa e, em termos populacionais, em ganhos de 8 a 10\% na economia de um país (ver em Ioschpe, G., A ignorância custa um mundo - $O$ valor da educação no desenvolvimento do Brasil, São Paulo: W11, 2004).

No Brasil, trabalhos do Instituto de Pesquisas Aplicadas (IPEA) comprovam que há uma relação diretamente proporcional entre a quantidade de anos de estudo e as chances de se conseguir um emprego ou manter uma carreira. Há ainda as seguintes relações: cada etapa de formação corresponde a um aumento de $50 \%$ sobre a remuneração anterior; um diploma representa em média $128 \%$ a mais de compensação em relação a quem se formou apenas no ensino médio; e quem comp leta um curso de pós-graduação possui chances de receber $66 \%$ a mais do que aquele que cursou apenas a graduação.

As estatísticas brasileiras sugerem que o ensino superior teve em passado recente uma fase de crescimento acelerado da demanda. Nos primeiros anos deste século, a matrícula nos cursos de graduação apresentou uma taxa média de expansão anual de $7 \%$ e atingiu o índice de $13 \%$ da população entre 18 e 24 anos matriculados em universidades. Entretanto, esse índice ainda não conseguiu posicionar o país em patamares similares aos de alguns países latino-americanos, como a Argentina e o Chile, que possuem $40 \%$ e $30 \%$, respectivamente.

Pode parecer paradoxal que, embora a oferta ainda seja suficiente apenas para atender cerca de $56 \%$ dos que se formam no ensino médio, os últimos anos apresentem um número significativo de vagas ociosas, muito provavelmente pela impossibilidade de os alunos arcarem com as mensalidades. Embora o preço possa não ser o fator mais relevante na competição pela demanda de ensino superior, sem dúvida representa fator importante num país que apresenta renda média anual de $\mathrm{R} \$ 6.473,00$ per capita (IBGE, 2002).

A Associação Brasileira de Mantenedores de Ensino Superior (ABMES), em estudo do $4^{\circ}$ Fórum Nacional do Ensino Superior Particular Brasileiro, em outubro de 2002, calculou que seria necessário 
$\mathrm{R}$ \$ 1,2 bilhão por ano em financiamentos estudantis para permitir o aproveitamento de vagas para 400 mil alunos que concluemo ensino médio e não conseguem inserção no ensino de terceiro grau por falta de recursos. Os dados disponíveis indicam que as políticas de financiamento atingem hoje apenas $10 \%$ dos estudantes, mas, segundo o Sindicato das Mantenedoras de Estabelecimentos de Ensino Superior Brasileiro, o ideal seria chegar ao patamar de 50\%. Uma das alternativas para o preenchimento dessas vagas é o ProUni - elaborado pelo governo federal e cuja implementação está planejada para 2005 -, que garante bolsas de estudos a estudantes carentes egressos de escolas públicas.

\section{A MULTIVERSIDADE NO ENSINO SUPERIOR}

A impressão que surge é de que Calderón utiliza o conceito de "multidiversidade" - de Clark Kerr como sinônimo de "universidade mercantil", significando "uma agência de prestação de serviços que atende a diversificadas demandas da sociedade e do mercado".

Embora a rigor possa parecer que se trate apenas de uma questão terminológica, o conceito utilizado por Calderón sugere que o objetivo mercantil reduz todas as formas da multidiversidade a uma eficiente "agência de emprego". Mesmo considerando pertinentes muitas de suas críticas ao modelo que apenas admite nesse universo a instituição atrelada à pesquisa, o conceito de Kerr parece atender melhor à realidade do mercado do ensino superior em geral. Sendo multidiverso, esse mercado comporta múltiplos modelos e tipos de instituições, destacando-se uma forma diferenciada, identificada neste artigo como "universidade", envolvendo atividades significantes que não são obrigatórias às demais instituições de ensino.

Entre as atividades essenciais de uma universidade está o ensino de qualidade, integrado necessariamente por atividades de pesquisa e atividades de extensão. Em seu texto, Calderón defende a idéia de que a pesquisa não é um pré-requisito essencial para o ensino de qualidade e excelência, e utiliza, como argumento reforçador, a ressalva de Silvio Botomé - no livro Pesquisa alienada e ensino alienante (Vozes, 1995) - de que o ensino, a pesquisa e a extensão seriam atividades universitárias e não "funções" da universidade. Talvez a preocupação sistemática de Botomé em mencionar as três atividades ou funções signifique exatamente o caráter imprescindível e indissociável destas.

A origem de grande parte da confusão parece residir no cuidado em valorizar individualmente cada atividade e função da universidade, que acabou separando-as, não apenas conceitualmente, mas organizacional (pró-reitorias ou gestões específicas) e operacionalmente. Há estudos que mostram que as atividades de ensino, pesquisa e extensão são reféns de um processo burocrático incontrolável, decorrente das estruturas piramidais de apoio às instituições de ensino superior, enquanto nos setores mais dinâmicos da sociedade vigoram formas mais flexíveis, mais abertas e mais horizontais. Modelos recentes e mais articulados já começam a experimentar alternativas integradas, a partir de projetos pedagógicos inovadores, introduzindo o aluno mais cedo em práticas investigativas e extensionistas que compõem os planos de ensino de forma interdisciplinar. 


\section{PROFISSIONAIS PARA O MERCADO VERSUS PRODUTORES DE CONHECIMENTO: OPOSIÇÃO SUPERADA}

Avanços teóricos e políticos permitem vislumbrar uma tendência de superação da antiga dicotomia, também presente no texto de Calderón, entre a opção de formar profissionais para o mercado centrado na transmissão de conhecimentos - e a capacitação dos alunos para a busca e produção de conhecimentos. Hoje é possível adotar um modelo de ensino voltado para desenvolver capacidades de busca do conhecimento, de formação de habilidades que atendam a demandas do mercado e de desenvolvimento de valores éticos e compromisso social, configurando o padrão de uma verdadeira universidade.

O mito da "torre de marfim", aplicado ao pretenso isolamento da universidade da realidade concreta, e, por outro lado, a desconfiança em relação aos interesses "capitalistas selvagens" dos empresários, tende a ficar cada vez mais fora de moda. Uma visão mais moderna são as parcerias, sob diversas formas, entre a universidade e todos os tipos de organizações sociais, destacando-se as empresas. Se a aversão de setores acadêmicos de considerar o ensino universitário como um produto comercializável, conforme denunciada por Calderón, pode ser considerada uma "defesa cega de interesses corporativos", o mesmo pode ser dito da recusa em se admitir um diferencial da universidade em relação a outras agências de ensino superior.

Mas para que os modelos integrais sejam eficazes, a universidade não pode se descuidar do estabelecimento de regras claras e de rígidos limites de independência em relação às empresas, imprescindíveis para que sua liberdade de pensamento e de criação não seja violada. Para Derek Bok no livro Universities in the Marketplace: The Commercialization of Higher Education (Princeton University Press, 2003) -, o bom êxito de uma universidade reside justamente em sua habilidade para vencer o desafio de compatibilizar a sua autonomia cognitiva, sua responsabilidade social e valores culturais com interesses políticos e econômicos, evitando o risco da "comercialização do ensino", que comprometeria a reputação da universidade frente à sociedade. A tarefa de negociação responsável exige que a universidade utilize uma linguagem menos interna corporis, estando receptiva a outras linguagens e sabendo se comunicar comum público não constituído apenas de acadêmicos.

A colaboração entre a universidade e o setor produtivo no Brasil ainda é tímida. Enquanto nos Estados Unidos $72 \%$ dos pesquisadores trabalham em empresas, em nosso país essa proporção é de apenas $11 \%$. Os pesquisadores das áreas das cềncias aplicadas necessitam de parcerias com o setor produtivo para transformar suas idéias em avanços tecnológicos, seja para a indústria ou para produtos e serviços que podem melhorar a vida da população. A Embraer é um exemplo freqüentemente citado nesse tipo de parceria, por envolver investimentos em educação, ciência e tecnologia. A empresa priorizou a formação de seu corpo de engenheiros e técnicos ao montar uma escola de engenharia aeronáutica e um centro de pesquisas em tecnologias aeronáuticas.

\section{EXIGÊNCIAS PARA AS UNIVERSIDADES}


A necessidade de desenvolver simultaneamente o treinamento profissional (ensinar), a capacidade para buscar e produzir conhecimento (pesquisar) e a formação de cidadãos (educar) é um desafio que se impõem à universidade, exigindo currículos inter e transdisciplinares. A exclusão de qualquer um desses elementos significaria configurar outro tipo de agência de ensino superior diferente das universidades.

O relatório da OCDE sobre a universidade do novo milênio privilegia a preparação ampla para uma grande variedade de condições imprevisíveis, em detrimento de um treinamento específico para tarefas que podem desaparecer nos próximos anos. Exige que as verdadeiras universidades atendam ao "dízimo da complexidade", reservando pelo menos $10 \%$ de sua carga horária a disciplinas de formação geral e humanística, com caráter interdisciplinar, ocupando-se de questões que extrapolem as fronteiras da especialização restrita, de forma a abarcar temas de caráter mais universal.

Segundo Edgard Morin, no livro A religação dos saberes - o desafio do século XXI (Bertrand Brasil, 2001), uma das tarefas principais da educação do futuro é garantir que o conhecimento consiga apreender problemas globais e fundamentais para neles serem inseridos os conhecimentos parciais e locais. Para ele, esse "paradigma da complexidade" é um "aprender a conhecer" voltado para a superação da supremacia do conhecimento fragmentado por disciplinas, que impede o vínculo entre as partes. A totalidade deve ser substituída por um modo de conhecimento capaz de apreender os objetos em seu contexto, sua complexidade, seu conjunto.

As orientações básicas da educação contemporânea reforçam principalmente a flexibilização de currículos e de disciplinas, do tempo e do espaço, do ensino e aprendizagem; o desenvolvimento da autonomia e da iniciativa dos alunos; a inter e a transdisciplinaridade como resposta à complexidade; os princípios de convivência, do não-preconceito, da aceitação das diferenças e da solidariedade. São elas que devem presidir todos os ordenamentos das universidades, desde a definição da missão, passando pelo projeto pedagógico, pelos planos de ensino, o desenvolvimento das atividades e o processo de avaliação.

A ligação cada vez mais tênue entre o trabalho e o emprego faz com que a formação se torne um investimento mais pessoal do que apenas uma condição necessária para um emprego específico. Sobrepondo competências e habilidades específicas, a "sociedade da informação" exige, dos profissionais, raciocínio lógico, desenvolvendo a habilidade para relacionar causas e efeitos, antecedentes e conseqüientes; capacidade de análise, de interpretação de dados, de identificação e compreensão das variáveis mais relevantes da realidade mutante; e, criatividade e iniciativa para propor soluções aos problemas desse ambiente incerto, formando pessoas para o enfrentamento de crises e de mudanças, não apenas aprender a aprender, mas também a desaprender o que não é mais importante.

De certa forma, no Seminário Internacional Universidade XXI, no final de 2003, houve a defesa desse modelo, considerado o mais adequado aos desafios do novo século e capaz de superar a "Velha Universidade" que, segundo a Carta aos Jovens de Todo o Mundo, "não dá conta do nosso Novo Mundo, não respeita as verdades produzidas fora de suas paredes e está presa a disciplinas compactadas e pré-formatadas, incapazes de lidar com o dinamismo e a complexidade dos tempos de hoje".

\section{O SEGMENTO PRIVADO E A EXPANSÃO DESCENTRALIZADA}


O crescimento do segmento privado no Brasil contribuiu para garantir a condição de universidade a algumas instituições privadas. Entre 1994 e 1998, o número de alunos matriculados no ensino público cresceu $16,5 \%$, enquanto no ensino privado esse aumento atingiu $36 \%$, elevando a participação desse segmento no ensino superior de $58 \%$ para $62 \%$.

Embora historicamente as melhores instituições públicas foram as que conseguiram alcançar o status de universidades, no momento atual a maturidade atingida por algumas instituições privadas - que investiram na titulação de seu corpo docente, na formação de grupos de pesquisa e em equipamentos e instalações adequadas aos projetos - já garante a sua inserção nessas "ilhas de competência". Seus esforços para capacitar seu corpo docente, produzir pesquisas e divulgar seus resultados, investir em tecnologia de última geração, descentralizar a oferta de seus cursos de graduação e pós-graduação, demonstram a opção por um nicho diferenciado do mercado de ensino superior.

Adicionalmente, os dados sobre a localização das instituições de ensino superior no Brasil apontam para uma tendência de descentralização da oferta mais acentuada nos anos recentes, com a criação de novos campi no interior. Se as metrópoles continuam mantendo importantes fatores multiplicadores de atração para as instituições de ensino - como a concentração populacional, oferta de professores titulados e recursos culturais -, existem também significativas variáveis que apontam para a pertinência da descentralização da oferta, como a múltiplas possibilidades de parcerias com o setor público e privado, local e regional, e a maior segurança das cidades menores. Alguns dos impactos da interiorização do ensino superior são tanto a criação de emprego e de renda - com valores salariais médios acima das preexistentes, afetando o nível e o padrão de consumo - como a indução de mudanças sociais e culturais. As instituições privadas foram as maiores responsáveis por esse fluxo direcionado ao interior, mas, recentemente, as IES públicas também reforçaram esse movimento. A USP, por exemplo, vem abrindo novos campi no interior de São Paulo.

\section{PESQUISA RELEVANTE}

A "universidade" possui como uma de suas especificidades a construção e a produção do conhecimento. Dessa forma, sua pesquisa deve objetivar responder às necessidades sociais prioritárias, atendendo a problemas cujas soluções sejam fundamentais para o desenvolvimento do país, da região, e para o aumento do bem-estar da população. Essa perspectiva corresponde ao conceito de investigação estratégica das universidades inovadoras, que, segundo Axel Didriksson, devem se comprometer em resolver problemas concretos, desenvolver tecnologias fundamentais, promover a geração e transferência de novos conhecimentos. Para o autor, a qualidade do processo educativo é medida pela utilidade social do conhecimento produzido e distribuído pela instituição

Embora os avanços do conhecimento e as mudanças tecnológicas estejam influenciando todos os setores e atividades humanas, algumas áreas ocuparam nos últimos anos - e tudo leva a crer que continuarão a ocupar - posição de destaque nos progressos científicos tecnológicos e, conseqüentemente, nos investimentos em pesquisa e desenvolvimento. Os indicadores de impacto medidos pelas publicações mais lidas e citadas no meio acadêmico mundial confirmam essa posição. É 


\section{PENSATA - O ENSINO SUPERIOR E A UNIVERSIDADE}

Moema Miranda de Siqueira

o caso da biotecnologia, da informática, dos sistemas de comunicação e de energia. O comércio eletrônico, por exemplo, cresce a taxas superiores a $15 \%$ ao ano, não havendo prognóstico de decréscimo nos próximos anos. Mesmo o mercado desses setores sendo altamente instável e dinâmico, o avanço nessas áreas, como o das telecomunicações, requer a continuidade de pesquisas e uma gama variada de profissionais qualificados. Há outras áreas que dependem de variáveis circunstanciais, como foi o caso da abertura do setor petrolífero no Brasil. Há uma demanda para a gestão do meio ambiente, em seus múltiplos e interdisciplinares aspectos, especialmente a questão energética, um dos mais inquietantes problemas, intimamente associados à crescente deterioração das condições ambientais e ao uso irresponsável dos recursos naturais.

Segundo documentos do Instituto Nacional de Pesquisas Educacionais (INEP), há ênfase na pesquisa regional e planejamento municipal em institutos ou agências de diferentes naturezas, sendo a gestão pública e da informação um espaço privilegiado, assim como os pequenos e médios negócios, especialmente por sua capacidade multiplicadora de geração de emprego e renda. No enfoque das especializações se destaca o comércio internacional, o comércio exterior, de saúde, o hospitalar, assim como o terceiro setor, que necessita cada vez mais de profissionais e voluntários competentes. Também há espaço em qualquer área para o empreendedor, e o ramo da construção civil e pesada, assim como outras atividades voltadas para a infra-estrutura, é apresentado pelos analistas como condicionado à taxa de crescimento do país. O turismo é outra área que tem sido privilegiada em todo o mundo inclusive também como alternativa à criação de emprego e renda, e à recuperação de áreas degradadas - em todas suas vertentes e novas especializações: de lazer, negócios, ecológico e saúde.

\section{O PAPEL DA PÓS-GRADUAÇÃO}

Nesse contexto, a pós-graduação constitui um segmento essencial, representando uma referência institucional indispensável para a qualificação do ensino superior e para a formação da base de recursos humanos necessária ao fortalecimento do potencial científico-tecnológico das universidades. Conforme demonstrado no IV Programa Nacional de Pós-Graduação (PNPG, 2004), os dados disponíveis mostram que é no seu interior que se desenvolve o essencial da atividade da pesquisa científica e tecnológica do país.

No entanto, o próprio PNPG reforça a opinião de que a dicotomia de formar profissionais versus formar pesquisadores nas universidades está superada. Alerta que a opção política por investir na formação pós-graduada de docentes e pesquisadores "não pode se descuidar do atendimento das diversas demandas de formação de profissionais de alto nível oriundas dos distintos mercados não acadêmicos do país". O cenário atual, de grandes inovações nos diferentes setores da economia e da sociedade, induz à procura de profissionais altamente especializados, cabendo à pós-graduação, além de produzir docentes e pesquisadores, atender à necessidade de formação desses profissionais .

Reforçando a idéia da vinculação entre ensino e pesquisa de qualidade, havia uma premissa implícita de que a melhoria da pós-graduação acarretaria de forma automática um aperfeiçoame nto da graduação. Não há dúvida quanto à sensível melhora na titulação dos docentes que atuam no ensino superior, mas a estrutura de funcionamento da graduação, os projetos pedagógicos e a produção acadêmica não apresentaram mudanças significativas. Constitui um desafio, a ser enfrentado, a busca 
de alternativas capazes de "envolver a pós-graduação no desenvolvimento institucional com efetiva articulação com o conjunto das atividades acadêmicas" (ver em IV PNPG).

\section{REGULAÇÃO E CORPORATIVISMO}

Finalizando as considerações estimuladas pelo texto por Calderón, e que certamente tanto extrapolaram o seu sentido quanto o seu conteúdo, é fundamental pelo menos uma referência à regulação do ensino superior no Brasil. Esse é talvez um dos temas mais tratados e mais plêmicos do momento, e a retomada da discussão acerca da reforma universitária o coloca em posição de destaque.

Parece não comportar dúvida a constatação de que o ensino superior brasileiro é fortemente regulado, e há certo consenso social acerca da necessidade dessa regulação, na medida em que o ensino é considerado um bem social. Embora o principal foco das discussões acerca dos limites dessa regulação, acirradas quando dos projetos de reforma universitária, diga respeito às instituições públicas de ensino, o segmento privado está sujeito a grande parte das normas e controles, além da dependência de financiamento direto ou indireto. Calderón defende o papel do Estado principalmente por meio da adoção de mecanismos de avaliação do mercado.

Talvez isso explique o mimetismo com que grande parte das instituições de ensino superior não públicas copia as estruturas organizacionais das IFES, mesmo sendo aquelas consideradas responsáveis pelas ineficiências históricas das universidades. E o que não dizer das "normas organizadoras de poder" dos professores, de que fala Pedro Lincoln de Matos (ver em $R A C$, v. 8, n. 2, 2004), de grande valor simbólico, compactuando com as resistências às mudanças? $\mathrm{Na}$ comunidade de pares que é a universidade, o poder do professor encontra respaldo em valores culturais, mas principalmente em seu "poder de interpretação", domínio da linguagem e do conhecimento científico; no "poder do critério", quando julga, avalia e decreta veredictos freqüentemente decisores de destinos e carreiras; no "poder da individualização final do saber", expressando-se e reforçando-se no quotidiano da sala de aula.

Os recentes processos de avaliação, com todas as suas limitações, tornaram mais sólida a posição de que a universidade - pública e privada - deve prestar contas de seu desempenho à sociedade, contribuindo para vencer o conservadorismo gerencial. Para isso, é importante que os interesses corporativistas não congelem as propostas de mudança, e que o cuidado com a qualidade acadêmica não sirva para encobrir a manutenção dos grupos no poder e os entraves a novos entrantes. Janine Ribeiro indaga se as associações nacionais de pesquisa e pós-graduação, ao buscarem uma maior interlocução entre os pesquisadores, não tenderiam a fechar ainda mais as áreas. Basta observar as condições estabelecidas nessas entidades para a candidatura a algum cargo de representação para se ter uma idéia da perpetuação dos grupos. Também as agências de fomento podem estar reforçando a manutenção das estruturas e dos grupos do poder, ao fixarem normas excessivamente rigorosas para concessão de auxílio, impedindo o acesso de grupos emergentes aos apoios. Ou ainda pior, a exclusividade concedida às instituições públicas de ensino para o atendimento a diversos editais, alijando as universidades confessionais, filantrópicas e privadas da seleção, como é o caso do Prodoc, concedendo bolsas a recém-doutorados para fixarem-se em programas de pós-graduação. 


\section{PENSATA - O ENSINO SUPERIOR E A UNIVERSIDADE}

Moema Miranda de Siqueira

A universidade do século XXI deverá elaborar formas gerenciais que melhorem seu desempenho em todos os aspectos - seja financeiro, pedagógico ou no seu relacionamento com a sociedade - e superar os resquícios medievais das "corporações de ofícios", viabilizando estruturas de poder mais abertas à renovação.

\section{Pensata convidada. Aprovada em 08.03.2004.}

\section{Moema Miranda de Siqueira}

Professora da UNIFENAS - Gestão de Pesquisa e Pós-Graduação. Doutora em Administração pela USP.

E-mail: moemams@uol.com.br 